\title{
Investigating The Prolonged Discharge Process in Pediatric Teaching Hospital of Tehran, Iran: A Cross-Sectional Study
}

\author{
Sodabeh Vatankhoh \\ Iran University of Medical Sciences \\ Azam Chopani \\ Iran University of Medical Sciences \\ Emir Tahmazi Aghdam \\ Iran University of Medical Sciences \\ Mohammad Esmaeel Tavakoli \\ Iran University of Medical Sciences \\ Nasrin Joudyian \\ Tabriz University of Medical Sciences \\ Hamideh Nafar ( $\sim$ nafar.h@IUMS.ac.ir) \\ Iran University of Medical Sciences
}

\section{Research Article}

Keywords: Discharge Process, Teaching Hospital, Pediatric Hospital

Posted Date: November 30th, 2021

DOI: https://doi.org/10.21203/rs.3.rs-1038665/v1

License: (c) (1) This work is licensed under a Creative Commons Attribution 4.0 International License. Read Full License 


\section{Abstract \\ Background}

The patient discharge process is one of the most important factors affecting patient satisfaction, which can affect the quality of services of hospitals, and its prolongation can be detrimental in bed management and result in admission delays for new patients. This study aimed to investigate the factors contributing to the prolongation of the discharge process in Tehran's pediatric teaching hospital.

\section{Methods}

The present study was a descriptive cross-sectional study carried out on 300 patients discharged from one of the pediatric teaching hospitals in Tehran in 2019. This study was conducted using a mixed-method and composed of two parts: quantitative and qualitative. Initially, in the quantitative stage, the statistical form was used, the average discharge time in different wards of the hospital was measured using the stopwatch method, and the data were analyzed using SPSS V. 25 software and descriptive statistics. Subsequently, to identify the causes of the prolonged process in some departments and identify practical solutions, a qualitative approach was used, including observations, file reviews, Focus Group Discussion (FGD), brainstorming with experts from the Quality Improvement Office, ward secretaries, clearance unit experts, pharmacy experts, and ward supervisors. Finally, the factors were prioritized and approved using the nominal group method.

\section{Results}

The average discharge time was 3 hours and 7 minutes; the shortest discharge time belonged to the blood ward, and the longest discharge time belonged to the kidney ward. The causes of delay in discharge were divided into two categories: organizational and human factors. The most crucial elements were the time required to issue discharge orders, write patient summaries, and maintain patient files.

\section{Conclusion}

For improving the quality of the discharge process and patient satisfaction, solutions such as having assistants write file summaries before the morning round, sending files out of the ward on time, hiring a circular secretary to collect patients' files from various wards, and controlling them using a standard checklist, nurses' training, and continuous supervision were proposed.

\section{Background}

The patient discharge process is one of the most important factors affecting patient satisfaction (1) and the quality of hospital services (2-4). Nowadays, following the rapid and increasing growth of science and technology, especially in medical and paramedical sciences, there is an urgent need to improve the quality of hospital services (1). Thus, prolonging the patient discharge process, as a negative factor in bed management, can result in admission delays for new patients, increased patient wait times for an empty bed, particularly in the emergency ward, and the emergency department refusing to accept new patients, all of which impose additional costs on the hospital, create other problems, and affect other hospital processes (4).

Previous studies have shown that the most important and effective factors influencing delay in the discharge process include delay in the patients' visit by doctors, delay in writing a patient file summary, lack of a hospital information system, lack of guidelines, and a lack of financial assistance to aid patients in paying their bills $(5,6)$.

Similarly, in Iran, physician-related factors, lack of health insurance, high volume of discharge files in the discharge unit due to process failure, disturbing the discharge process by the patient's companions, non-referral of patient's companions to discharge their patient, delays in sending pharmacy and laboratory settlement sheets, delays in registering and sending information by the treatment department, lack of workforce in the discharge unit and defects in the hospital notification system have been determined as factors leading to discharge process prolongation $(1,4,7,8)$.

Therefore, it seems that the discharge process is a significant challenge in the management of hospitals, and improving this process is a crucial strategy based on which all hospital activities are defined, developed, and implemented (4). On the other hand, the discharge process in pediatric hospitals is critical because children are frequently unable to be left alone in the hospital, and parents who live in nearby villages or towns must commute between home and the hospital to care for their children (6).

This study aims to investigate the reasons for the prolonged discharge process in a specialized pediatric teaching hospital and to provide practical solutions that may be used to improve the discharge process, reduce costs, decrease the waiting time, and improve patient satisfaction.

\section{Methods}

This cross-sectional descriptive study was conducted in 2019 at one of Tehran's pediatric teaching hospitals. This study used a mixed-methods approach and is divided into two sections: quantitative and qualitative.

In the quantitative step, which aimed to measure the average discharge time, the sample size was calculated according to the Cochran formula for sample size determination, i.e., $\left(n=\mathrm{Nz}^{2} \mathrm{pq} /\left(\mathrm{Nd}^{2}+\mathrm{Z}^{2} \mathrm{pq}\right)\right.$; accordingly, a total of 300 discharged patients were randomly selected. Then, the various stations into which the 
file is routed during the discharge process were identified, and the data collection form was created accordingly. After that, the arrival and departure times for each station were determined using this form. The form's validity was verified by the officials of the various departments involved in the clearance process, and to obtain reliable results, individuals were given the necessary training to measure time accurately.

All experimental protocols were approved by the University of Iran Medical Science Research Ethics Committee. In order to gather data, the researchers obtained the necessary approvs by providing explanations to the hospital management and security about the objectives of the study. all methods were carried out in accordance with relevant guidelines and regulations and informed consent was obtained from all participants.

For two weeks, the discharge process of all patients discharged from all hospital wards was monitored, and the time of entry and exit of the file to the designated stations was measured using the stopwatch technique. The data were entered into the SPSS V. 25 software, and descriptive statistics were used to analyze them.

In the qualitative step of the study, to identify the causes of the prolonged discharge process in some departments and propose practical solutions, a qualitative approach was used, including observation, file reviews, FGD, brainstorming with experts of the quality improvement office, ward secretaries, clearance unit experts, pharmacy experts, and ward supervisors. Each meeting was attended by 5 to 8 people, and information was collected through FGD, brainstorming, and aggregation of opinions, where all participants' views were obtained, and all meetings were recorded. Then, using tables, factor groups were formed, and finally, based on group consensus, the causes and practical solutions were identified, prioritized, and approved using the nominal group method.

\section{Results}

The results of this study are summarized in two tables. Table 1 shows the time of entry and exit of the file to each station and the average time that the file remains in each of the timed stations.

According to Table 1, the average discharge time in the hospital was three hours and seven minutes, the shortest discharge time belonged to the blood ward with an average of two hours and 22 minutes, and the longest discharge time belonged to the kidney ward with four hours and ten minutes. Also, the process that took the most time was writing the case summary after the approval order with an average of 106 minutes, which took the most time in all sections, and the process that took the minimum time was the workflow. Leaving the file from the ward and pharmacy took an average of 10 minutes.

Based on the results of FGD, observations, and file reviews, the causes of delay in discharge were divided into two categories: organizational and human factors (Table 2).

In terms of organizational factors, the findings indicated that most wards experienced delays in discharge time due to the simultaneous discharge of multiple patients, except for the general ward and kidney ward, where the high volume of patients caused the delay. Due to the existence of an average of 20-34 beds in each ward, the shortage of secretaries was sometimes evident, so the secretary of one ward was responsible for two wards simultaneously, and as a result, the accumulation of work caused some tasks to be postponed. One of the primary reasons for the prolonged patient discharge process was that the companions were informed of the patient's discharge based on what they had heard from the physician and immediately began asking questions about the patient's discharge. Due to their early arrival at the discharge unit, they believed there was a delay in the process.

In terms of human factors, the current study's findings indicated that this could be attributed to incorrect case summaries written by the doctor and assistants and incorrect drug return registration by the responsible nurse, which results in the files being returned to the ward for correction. The nurses' unfamiliarity with the Health Information System (HIS), as well as a lack of feedback regarding the completion of the files' checklist, the early presence of patients' companions to perform discharge tasks, and the absence of a doctor's signature at the end of the report all contributed to the length of the discharge process.

\section{Discussion}

Factors with the most significant impact on prolonging patients' discharge time included prolongation of issuing the discharge order, illegibility of orders, the lengthening of the time required to write and control a patient file summary, and in some wards, the delay in file exit from the ward. Due to the educational nature of the hospital and the practice of morning rounds, the discharge order is typically issued following morning rounds, and the process of checking files and writing a summary following morning rounds appears to prolong the discharge process. In some cases, the lack of a workforce and the lack of necessary skills and training for staff to work with hospital information systems has led to a prolongation of this process.

A study by Patel et al. identified many barriers for discharging in a hospital, including delays in diagnostic tests and counseling, poor communication between members of the team of caregivers, and between patients and service providers (9). Statile et al. suggested a failure in communication and inadequate training as obstacles in discharging patients on time (10). Zoucha et al. stated that issues related to discharge time, shortage of medical staff, lack of a monitoring and evaluation system and effective training, as well as staffs' waiting for the attending physician of the ward, asking for ancillary services such as counseling, were the most important reasons for prolongation of the discharge process (11).

The study conducted by Ragavan et al. suggested patient unpreparedness, prolonged time to receive a consultation and its delivery, location of hospital facilities, communication between staff and patient, timely notification of discharge and lack of standardization of discharge process, and delays in the testing and counseling process, especially on weekends were the main reasons for late discharge (12). The results of these studies are consistent with the results of the present study. 
Some of the solutions obtained in this study to improve the discharge period are writing the file summary by the residents before the start of the medical students' training classes, releasing a resident from the morning program in a rotating manner to write the patient file summary, reducing the time that the file stays in the writing file summary stage, improving attention to detail of the nurse in charge of file control to minimize the amount of returned issues, a timely file sending out of the ward, creating an electronic health file and recording patient information from the time of admission in the hospital to secretaries' excessive commuting between the wards, which in addition to reducing the delay in discharge, patients' satisfaction is also obtained.

By rotating a secretary between wards to collect and control patient files using a written checklist if the electronic file is not set up or if performing periodic and accurate timing to evaluate the ward's performance is too time-consuming, specialized nurse training on the Information Technology (IT) unit, as well as educational supervisor training, continuous monitoring by the head nurse to correct returned drugs, particularly in patients who have been circulated between wards, accurate notification of discharge time and information about patients' companions, and writing the file summary, which is a time-consuming process. Finn et al. suggested that the assignment of supporting staff to complete tasks, such as completing discharge documents, setting up follow-up appointments and prescriptions, communicating with other nurses and physicians for discharge, and answering discharged patients' questions, has improved many aspects of the discharge process (13).

Patel et al. believed that effective collaboration between multidisciplinary teams and patients positively affects discharge (9). Zoucha et al. recommended some strategies, such as preparing discharge sheets and medications the night before discharge, using checklists, having enough people on the medical team, providing instant feedback to staff and personnel, and using multidisciplinary medical staff to improve the discharge process (11). Rohatgi et al. suggested that solutions such as allocating sufficient resources and staff over the weekend to ensure safe and timely discharge of patients can help maintain the operational capacity of medical centers (14).

Harlan et al. also considered strategies such as quality improvement, including training and electronic discharge guidelines to effectively improve the discharge process in pediatric hospitals (15). Finally, Wu et al. believed that solutions, such as creating proactive programs for discharge, including educating families and patients about the disease and the discharge schedule, establishing and updating scheduled discharge times, and ensuring that financial problems do not prevent discharge could improve the discharge process (16), where the results of their study are in line with the findings of the present study.

\section{Limitations}

Despite the limitations of this study, we attempted to cover all aspects of the discharge process. During the FGD and interviews, specialist physicians and medical students were not present, and thus their perspectives were lost; during the quantitative phase, technical difficulties with the recorder occasionally resulted in missing data.

\section{Conclusion}

Solutions such as residents writing file summaries before the morning round, timely removal of files from the ward, hiring a circular secretary to collect patients' files from various wards and controlling them using a standard checklist, nurse training, and continuous supervision can all help improve the quality of the discharge process and patient satisfaction. It is recommended that additional studies should be designed and conducted to assess the proposed solutions' impact on reducing discharge process time, improving discharge process quality, and increasing patient satisfaction.

\section{Abbreviations}

FGD: Focus Group Discussion

HIS: Health Information System

IT: Information Technology

\section{Declarations}

Ethics approval and consent to participate: This study was received ethical approval from the University of Iran Medical Science Research Ethics Committee (registration code: IR.IUMS.REC.1400.163). Participants provided informed consent.

Consent for publication: Not applicable

Availability of data and materials: All data generated or analyzed during this study are included in this published article. There is no supplemental material to present.

Competing interests: The authors declare that there is no conflict of interests

Funding: No external funds were granted for this research.

Authors' contributions: HN, ET, and MT participated in designing the study, gathering the data, analyzing and interpreting the data, and writing the manuscript. $\mathrm{HN}, \mathrm{ET}$, and $\mathrm{ACH}$ contributed to designing the study, collecting the data, analyzing and interpreting the data, and writing the manuscript. SV, HN, and $\mathrm{NJ}$ worked on developing, editing, and finalizing the manuscript draft. All authors read and approved the manuscript. 
Acknowledgments: The authors wish to express their gratitude to the pediatric teaching hospital (Hazrat Ali Asghar) in Tehran for providing the research setting and supportive atmosphere and Parvin Ebrahimi Professor of HealthCare Services Mnagement, Iran University of Medical Sciences for valuable advice.

\section{References}

1. Vanaki Z, Habibipour B. The assessment of effective discharge planning on patients satisfaction. Avicenna Journal of Nursing and Midwifery Care. 2008;16(2):25-35.

2. El-Eid GR, Kaddoum R, Tamim H, Hitti EA. Improving hospital discharge time: a successful implementation of six sigma methodology. Medicine. 2015;94(12).

3. Nezhad Jafari N, Khatibi T. Prioritizing the causes of disruption in the discharge process of hospitalized patients[in Persian]. International conference on industrial engineering and management2016.

4. Van Emden DMD, Ros WJ, Berns MP. Transition of care: an evaluation of the role of the discharge liaison nurse in the Netherlands. Journal of Advanced Nursing. 1999;30(5):1186-94.

5. Fazel Asl N, Ghaffari F, Nasiripour AA. Determining Factors on Hospital Discharge Process Via Data-Mining Method Administered at Shahid Modares Hospital, Tehran. Journal of Payavard Salamat. 2018 Jan 10;11(5):509-17.

6. Henwood M. Effective partnership working: a case study of hospital discharge. Health \& social care in the community. 2006;14(5):400-7.

7. Ebrahimipour H, VAFAEI NA, NOURI GA, Esmaeili H, Jamili S. Studying waiting time of patient during discharge process in clinical departments of Imam Reza hospital affiliated with Mashhad University Of Medical Science In 2014. 2015.

8. Yarmohammadian M, Khosravizadeh O, Alirezaei S, Doosty F. Impact of business process model on improving the discharge process in teaching hospital of Ghaem, Mashhad. Journal of Health Administration (JHA). 2015;18(61).

9. Patel H, Yirdaw E, Yu A, Slater L, Perica K, Pierce RG, et al. Improving early discharge using a team-based structure for discharge multidisciplinary rounds. Professional case management. 2019;24(2):83-9.

10. Statile A, Jerardi K, Brady PW. Improving the readability of pediatric hospital medicine discharge instructions. Journal of hospital medicine. 2017;12(7).

11. Zoucha J, Hull M, Keniston A, Mastalerz K, Quinn R, Tsai A, et al. Barriers to Early Hospital Discharge: A Cross-Sectional Study at Five Academic Hospitals. Journal of hospital medicine. 2018;13(12):816-22.

12. Ragavan MV, Svec D, Shieh L. Barriers to timely discharge from the general medicine service at an academic teaching hospital. Postgraduate medical journal. 2017;93(1103):528-33.

13. Finn KM, Heffner R, Chang Y, Bazari H, Hunt D, Pickell K, et al. Improving the discharge process by embedding a discharge facilitator in a resident team. Journal of hospital medicine. 2011;6(9):494-500.

14. Rohatgi N, Kane M, Winget M, Haji-Sheikhi F, Ahuja N. Factors associated with delayed discharge on general medicine service at an academic medical center. The Journal for Healthcare Quality (JHQ). 2018;40(6):329-35.

15. Harlan GA, Nkoy FL, Srivastava R, Lattin G, Wolfe D, Mundorff MB, et al. Improving transitions of care at hospital discharge-implications for pediatric hospitalists and primary care providers. Journal for Healthcare Quality. 2010;32(5):51-60.

16. Wu S, Tyler A, Logsdon T, Holmes NM, Balkian A, Brittan M, et al. A Quality Improvement Collaborative to Improve the Discharge Process for Hospitalized Children. Pediatrics. 2016;138(2):e20143604.

\section{Tables}

Table 1. Key data regarding the time of the file's entry and exit from each station in the wards 


\begin{tabular}{|c|c|c|c|c|c|c|c|c|c|c|c|c|}
\hline \multirow[t]{2}{*}{ Ward } & & \multicolumn{6}{|c|}{ each station Time of file entry to } & \multicolumn{5}{|c|}{ Process duration at each station } \\
\hline & & $\begin{array}{l}\text { Discharge } \\
\text { Order }\end{array}$ & $\begin{array}{l}\text { File } \\
\text { Summary }\end{array}$ & $\begin{array}{l}\text { File } \\
\text { Control }\end{array}$ & $\begin{array}{l}\text { Exit } \\
\text { from } \\
\text { Ward }\end{array}$ & $\begin{array}{l}\text { Exit } \\
\text { from } \\
\text { Pharmacy }\end{array}$ & Discharge & $\begin{array}{l}\text { From } \\
\text { order to } \\
\text { Summary }\end{array}$ & $\begin{array}{l}\text { From } \\
\text { Summary } \\
\text { to Control }\end{array}$ & $\begin{array}{l}\text { From } \\
\text { control } \\
\text { to } E \text {. } \\
\text { from } \\
\text { Ward }\end{array}$ & $\begin{array}{l}\text { From E. } \\
\text { Ward to E. } \\
\text { Pharmacy }\end{array}$ & $\begin{array}{l}\text { From } \\
\text { Pharmac } \\
\text { to } \\
\text { Discharg } \\
\text { U. }\end{array}$ \\
\hline \multirow[t]{2}{*}{ Blood } & $\mathrm{N}$ & 47 & 47 & 47 & 47 & 47 & 47 & 47 & 47 & 47 & 47 & 47 \\
\hline & Average & $8: 42$ & $9: 14$ & $10: 11$ & $10: 40$ & $10: 53$ & 11:05 & $0: 31: 42$ & $0: 57: 20$ & $0: 28: 15$ & $0: 13: 42$ & $0: 11: 39$ \\
\hline \multirow[t]{2}{*}{ general } & $\mathrm{N}$ & 38 & 38 & 38 & 38 & 38 & 38 & 38 & 38 & 38 & 38 & 38 \\
\hline & Average & $10: 10$ & $11: 57$ & $11: 38$ & $12: 28$ & $12: 40$ & $12: 50$ & $1: 46: 20$ & $-0: 18: 15$ & $0: 49: 23$ & $0: 11: 52$ & $0: 10: 44$ \\
\hline \multirow[t]{2}{*}{ Kidney } & $\mathrm{N}$ & 31 & 31 & 31 & 31 & 31 & 31 & 31 & 31 & 31 & 31 & 31 \\
\hline & Average & $8: 27$ & $11: 15$ & $11: 02$ & $12: 19$ & $12: 24$ & $12: 38$ & $2: 47: 46$ & $-0: 12: 11$ & 1:16:05 & 0:05:03 & $0: 13: 56$ \\
\hline \multirow[t]{2}{*}{$\mathrm{NICU}$} & $\mathrm{N}$ & 30 & 30 & 30 & 30 & 30 & 30 & 30 & 30 & 30 & 30 & 30 \\
\hline & Average & $10: 30$ & $12: 11$ & $12: 29$ & $12: 54$ & 13:01 & $13: 10$ & $1: 41: 40$ & $0: 17: 30$ & $0: 25: 00$ & 0:07:04 & 0:09:06 \\
\hline \multirow[t]{2}{*}{ Surgery } & $\mathrm{N}$ & 31 & 31 & 31 & 31 & 31 & 30 & 31 & 31 & 31 & 31 & 30 \\
\hline & Average & $9: 01$ & $11: 09$ & $11: 24$ & $11: 42$ & $11: 59$ & $12: 08$ & $2: 07: 36$ & $0: 15: 36$ & $0: 17: 27$ & $0: 17: 36$ & $0: 10: 32$ \\
\hline
\end{tabular}

Due to technical limitations, Table 2 is only available as a download in the Supplemental Files section.

\section{Supplementary Files}

This is a list of supplementary files associated with this preprint. Click to download.

- Table2.docx 